\section{Los Sistemas de Información Geográfica como herramienta para la extensión universitaria}

Bianca Vanesa Freddo

freddobianca@gmail.com

Cristina Beatriz Massera

cristinamassera@gmail.com

Universidad Nacional de la Patagonia San Juan Bosco. Consejo Nacional de Investigaciones Científicas y Técnicas (CONICET) y Consejo Latinoamericano de Ciencias Sociales (CLACSO),

Argentina.
A 100 años de la Reforma Universitaria de 1918 / Intervenciones

RECEPCIÓN: 29/06/17

ACEPTACIÓN FINAL: 02/10/17

\section{Resumen}

En América Latina, los desafíos de la universidad pública se han ido transformando. En el siglo XXI la extensión está pensada desde la esfera social, como un proceso donde se refuerzan el vínculo y las implicancias políticas y culturales.

En ciencias sociales, los fenómenos se producen en un determinado espacio geográfico, y en consecuencia pueden ser georreferenciados a partir de un sistema de coordenadas espacio-temporal. En este contexto, los Sistemas de Información Geográfica (SIG) son una herramienta para la investigación y facilitan la comprensión e interpretación de los fenómenos territoriales.

El objetivo es brindar conocimientos básicos sobre SIG, generar bases teóricoprácticas para el manejo de herramientas geoespaciales y aplicar los conocimientos adquiridos en la resolución de problemas territoriales. A partir de la metodología teórico-práctica los resultados fueron las diversas temáticas territoriales y el intercambio de saberes del territorio vivido.

\section{Resumo}

Na América Latina, os desafios das universidades públicas têm mudado. No século 21 , a extensão é pensada a partir da esfera social, como um processo que reforça o vínculo e as implicações políticas e culturais.

Nas ciências sociais, os fenômenos ocorrem em um determinado espaço geográfico, conseqüentemente podem ser georreferenciados a partir de um sistema de coordenadas espaço-temporais. Neste contexto, os Sistemas de Informação Geográfica (SIG) são uma ferramenta de pesquisa e facilitam a compreensão e interpretação dos fenômenos territoriais.

O objetivo é fornecer conhecimento básico sobre SIG, gerar bases teórico-práticas para o gerenciamento de ferramentas geoespaciais e aplicar os conhecimentos adquiridos na resolução de problemas territoriais. A partir da metodologia teórico-prática, os resultados foram os vários temas territoriais e a troca de conhecimentos sobre o território vivido.

Palavras chave

- Análise espacial

- Território

- Qgis

- Extensão

- Práticas
Para citación de este artículo

Freddo, B. V. y Massera, C. B. (2017).Los Sistemas de Información Geográfica como herramienta para la extensión universitaria. Revista $+E$ versión en línea, 7(7), 320-329. Santa Fe, Argentina: Ediciones UNL. 


\section{Introducción}

El presente trabajo es resultado del proyecto de extensión "Los Sistemas de Información Geográfica (SIG) y sus aplicaciones al medio ambiente", desarrollado en el Departamento de Geografía de la Facultad de Humanidades y Ciencias Sociales de la Universidad Nacional de la Patagonia San Juan Bosco, dictado en el Núcleo de Acceso al Conocimiento (NAC) de la Secretaría de Cultura y Educación de la Municipalidad de Trevelin en mayo de 2016. Este artículo explica una experiencia de enseñanza desde la Geografía con soporte en los Sistemas de Información Geográfica (SIG), denominada: "Los Sistemas de Información Geográfica y sus aplicaciones al medio ambiente", con el principal objetivo de enseñar los SIG mediante el uso de herramientas, el manejo de información geoespacial y los conocimientos empíricos. Esto es posible en virtud de los materiales didácticos disponibles en la web a través de sitios oficiales. El artículo tiene la siguiente estructura: en primer lugar, se hace una introducción a los principales conceptos en torno a los SIG, componentes, funciones, etapas de un proyecto, el análisis espacial y la cartografía temática. La segunda parte describe cuáles han sido los recursos didácticos para emprender la enseñanza de los SIG a partir de problemáticas locales y regionales, con la utilización de información geoespacial y cartografía de base. La tercera parte comprende las experiencias prácticas a partir de los recursos y sus aplicaciones con relación al área de estudio comprendida por las ciudades de Esquel y Trevelin, ambas ubicadas en la Comarca Andina, al oeste de la provincia de Chubut. Por último, se apunta a destacar la importancia de las nuevas tecnologías aplicadas desde el ámbito de la extensión universitaria y el uso de la información geográfica para fines didácticos como una nueva posibilidad de trabajo interdisciplinario en diversos ámbitos.

\section{Los Sistemas de Información Geográfica}

Desde la Geografía como disciplina social nos encontramos con una nueva área de conocimiento, Ios SIG, definida como un conjunto de herramientas que permiten generar, procesar y representar información geográfica (Chuvieco, 2008). Brindan la posibilidad de trabajar metodológicamente con diversos componentes para comprender la dinámica y organización del territorio a partir de capas de información que pueden ser analizadas de manera individual o colectiva, es decir, sus atributos se pueden relacionar con otra información.
Los SIG han sido utilizados desde sus inicios por distintas ciencias para la resolución de problemas socioespaciales, y por eso es considerada una herramienta interdisciplinaria. Sus principales componentes son software, hardware, espacio físico, base de datos y recursos humanos. En términos de Buzai (2016), la finalidad amplia de los SIG es la de combinar las bases de datos alfanuméricas para representar esos datos dentro de un sistema de coordenadas y posteriormente realizar un adecuado tratamiento espacial de los mismos.

Son una herramienta de gran alcance dentro de la informática que proporciona un marco en el cual podemos analizar el espacio geográfico. Los SIG han introducido nuevos conceptos relacionados con el análisis y modelaje de datos complejos, mapas interactivos y la suma de gran variedad de datos con información geoespacial que además permiten integrar formatos de visualización y de procesamiento de datos georreferenciados cuyas aplicaciones se desarrollan para la gestión y planificación que facilitan la toma de decisiones en procesos complejos de desarrollo (Llanes Guerra, 2010).

Sin embargo, también se debe destacar las principales limitaciones a la hora de trabajar con información geoespacial: el acceso a la información geoespacial, la calidad e interoperabilidad del dato geográfico, la capacitación de los equipos técnicos, la construcción y actualización de la información, entre otros. Si bien la primera problemática se está abordando desde las distintas instituciones a través de geoservidores y la presencia del Infraestructura de Datos Espaciales de la República Argentina (IDERA), ${ }^{1}$ aún es una práctica que no logra desarrollarse con intensidad.

Cabe recordar que uno de los componentes para elaborar un SIG es la información, y se requiere de datos de soporte para que pueda resolver los problemas y contestar a preguntas. La obtención de esos datos necesita una conexión formal con diversas instituciones y es un proceso que con frecuencia demora. En este punto, se debe resaltar que la información provista por entes estatales debe ser de acceso público con las restricciones correspondientes a la sensibilidad de los datos trabajados. ${ }^{2}$ Es así que en los grupos de trabajo es recurrente la problemática vinculada a la gestión de la información local; esto apareció en el equipo y generó un debate sobre el acceso a la información geográfica local y la ausencia de datos. En tales circunstancias se apela al trabajo y relevamiento de campo para la actualización o para generar nueva información sobre el área de estudio. Pero existen casos donde no se puede
1) Iniciativa desde el año 2007 y que actualmente cuenta con la adhesión y publicación de información de una importante cantidad de organismos nacionales, provinciales, municipales y de investigación. Las acciones tendientes a institucionalizar IDERA son asumidas desde los diferentes niveles del Estado como una responsabilidad intrínseca e indelegable hacia la sociedad a la que es útil.

2) Así lo define IDERA acorde con

las políticas instaladas en materia de gobierno electrónico y libre acceso a la información propias de un Estado moderno: "la Información Geográfica es un bien público y, su acceso y uso, debe ser considerado como un servicio público". 
apelar al relevamiento personal porque la información geográfica es elaborada por instituciones estatales con parámetros definidos que hacen a la legitimidad de la información, por ejemplo: límites provinciales, límites internacionales, líneas de costas, accidentes geográficos, entre otros.

\section{Análisis espacial y cartografía temática}

El análisis espacial concentra conceptos de la Geografía cuyo objeto de estudio es el espacio geográfico. Buzai (2016) destaca que el análisis espacial requiere de técnicas estadísticas y matemáticas aplicadas al estudio de datos distribuidos en un determinado espacio geográfico. Según él, los cinco conceptos básicos para realizar análisis espacial con los SIG son:

- Localización: ubicación específica en el espacio geográfico.

- El Sitio: sistema de referencia de coordenadas.

- Distribución espacial: el conjunto de entidades de un mismo tipo repartidas de una forma determinada.

- Asociación espacial: correspondencias al comparar distintas distribuciones.

La Geografía desarrolló un método específico: la superposición cartográfica; la interacción espacial es la estructuración de un espacio relacional en el cual las localizaciones, distancias y vínculos son fundamentales; la evolución espacial se incorpora el concepto temporal; la integración es la combinación de los resultados empíricos a partir del uso de los conceptos analizados. El análisis espacial, al igual que los otros geoprocesos que se desarrollan con los SIG, tiene la finalidad de representar el área de estudio a través de un mapa temático o mapa síntesis. A continuación se proporcionan algunas definiciones de cartografía temática.

Tal como la definición de los SIG, la cartografía temática encuentra muchas definiciones. Según la ICA (Asociación Internacional de Cartografía), "es aquella que está diseñada para mostrar características o conceptos particulares. En el uso convencional de los mapas, este término excluye los mapas topográficos". La representación de la superficie terrestre es la tarea de la cartografía, principalmente desde el punto de vista geométrico. Para realizar un mapa temático son necesarios elementos geográficos de referencia, también denominados "mapa base". Entre los múltiples elementos que debe contener el mapa se destacan los siguientes: tema, área de estudio, orientación, leyenda, proyección, escala, fuente de información y autor.
Existen dos tipos de cartografía temática: los mapas cualitativos y los mapas cuantitativos. Los cualitativos muestran la distribución espacial de un grupo de datos en escala de medidas nominales. Por ejemplo, mapas de suelos, geológicos, étnicos, etc.

Los cuantitativos representan aspectos espaciales de datos numéricos, por lo general se usan escala de intervalos e índices.

\section{Los Sistemas de Información Geográfica como recurso didáctico}

Los recursos didácticos que se han implementado han seguido la siguiente estructura, atendiendo el proceso de la enseñanza de un software y la gestión de problemáticas socioambientales. Como experiencia pedagógica, se persiguen los lineamientos que propone Zappettini (2007) en cuanto a que toda propuesta didáctica se estructura con relación a tres interrogantes generales: ¿qué enseñar?: el objeto de conocimiento. ¿Cómo enseñar?: la metodología a implementar. ¿Para qué enseñar?: los objetivos perseguidos.

La información geográfica es un recurso didáctico (Masot, 2010) que permite explorar, conocer, analizar y describir el territorio. El docente cuenta con múltiples herramientas para transformar, analizar, simular y relacionar datos cuantitativos-cualitativos y así fomentar el conocimiento colectivo. Es un requisito formar a los estudiantes en el uso del software, pero también enseñar facultades para acceder, seleccionar y construir información geoespacial según las necesidades del usuario.

Asimismo, Quiroz Ortuño (2010) destaca que los SIG son herramientas utilizadas para la toma de decisiones, aunque son necesario no solo su conocimiento y manejo sino que también se deben desarrollar capacidades complementarias: poder trabajar en equipos multidisciplinarios, manejo de bibliografía especializada, conocimiento de métodos y técnicas participativas, habilidades en la coordinación de grupos y poder analizar información proveniente de diversas fuentes.

El uso de los SIG no es solamente la utilización de un software, es el conocimiento de la información geoespacial desagrupada en unidades espaciales, aprendidas bajo modelos y formas de organización territorial en un determinado marco teórico. Este último puede provenir de distintas disciplinas, lo que requiere la investigación de la problemática en profundidad. La presentación de la información geográfica debe contemplar este contexto de trabajo. Se presentan a continuación los sitios para acceder a la información geográfica: Tablas $N^{\circ} 1$ y 2 . 
Tabla $N^{\circ} 1$. Recursos y materiales

\begin{tabular}{|c|c|c|}
\hline Software & Descripción & Web \\
\hline Qgis & $\begin{array}{l}\text { Código abierto. } \\
\text { Permite la gestión y } \\
\text { manejo de los datos } \\
\text { espaciales. }\end{array}$ & www.qgis.org/es/site/ \\
\hline Google Earth Pro & $\begin{array}{l}\text { Visualiza cartografía a } \\
\text { escala mundial con base } \\
\text { en imagen satelital. }\end{array}$ & www.qgis.org/es/site \\
\hline $\begin{array}{l}\text { Servicio Geológico } \\
\text { de Estados Unidos } \\
\text { (USGS) }\end{array}$ & $\begin{array}{l}\text { Descarga gratuita de } \\
\text { recursos satelitales. }\end{array}$ & www.earthexplorer.usgs.gov \\
\hline Google Maps & $\begin{array}{l}\text { Servidor de mapas en } \\
\text { la web. }\end{array}$ & www.google.com.ar/maps/ \\
\hline
\end{tabular}

Fuente: elaboración propia.

En los últimos años es relevante la participación de los portales geoespaciales que permiten realizar consultas y descarga de información geográfica. Existen diferentes servidores, y entre los más utilizados están WMS (Web Map Service), que hace factible visualizar información proveniente de otros servidores, y WFS (Web Features Services), que accede a los datos. Es fundamental la liberación de información geoespacial en distintos formatos para la elaboración de cartografía y la democratización del acceso de la información producida por el Estado.

\section{Experiencias prácticas en la provincia de Chubut}

Aquí presentamos las experiencias teórico-prácticas sobre el levantamiento de información con el uso de los Sistema de Posicionamiento Global (GPS) y posterior integración al proyecto SIG con relación al área de estudio comprendida por las ciudades de Esquel y Trevelin, ambas ubicadas en la Comarca Andina, al oeste de la provincia de Chubut. Este espacio generó la discusión sobre la información geográfica local y la ausencia de datos para la construcción de mapas síntesis. En tales circunstancias se apeló al trabajo y relevamiento de campo para la actualización o generar nueva información sobre el área de estudio.
Tabla $\mathbf{N}^{\circ}$ 2. Sitios web de información geoespacial en Argentina

\begin{tabular}{|c|c|c|}
\hline Intitución & Formato & Sitio \\
\hline IGN & $\begin{array}{l}\text { Visor web } \\
\text { Servicio WMS } \\
\text { Catálogo de metadatos } \\
\text { CSW }\end{array}$ & www.ign.gob.ar \\
\hline IDERA & $\begin{array}{l}\text { Visor web. } \\
\text { Servicio WMS } \\
\text { Catálogo de metadatos } \\
\text { CSW }\end{array}$ & www.idera.gob.ar \\
\hline CONAE & Visor web & www.conae.gov.ar \\
\hline INTA & Visor web & $\begin{array}{l}\text { http://geointa.inta.gov.ar/ } \\
\text { visor }\end{array}$ \\
\hline SEGEMAR & Visor web & http://sig.segemar.gov.ar/ \\
\hline $\begin{array}{l}\text { Ministerio de } \\
\text { Educación }\end{array}$ & Visor web & $\begin{array}{l}\text { http://www.mapaeducativo } \\
\text { edu.ar/ }\end{array}$ \\
\hline $\begin{array}{l}\text { Ministerio de } \\
\text { Energía y Minería }\end{array}$ & $\begin{array}{l}\text { Visor web. } \\
\text { Servicio WMS } \\
\text { Catálogo de metadatos } \\
\text { CSW }\end{array}$ & $\begin{array}{l}\text { http://sig.se.gob.ar/ } \\
\text { geoportal/ }\end{array}$ \\
\hline $\begin{array}{l}\text { Secretaría } \\
\text { de Ambiente } \\
\text { y Desarrollo } \\
\text { Sustentable }\end{array}$ & Visor web & $\begin{array}{l}\text { http://ambiente.gob.ar/ } \\
\text { http://mapas.ambiente. } \\
\text { gob.ar/ }\end{array}$ \\
\hline
\end{tabular}

Fuente: elaboración propia.

\section{G6}

Los SIG han introducido nuevos conceptos

relacionados con el análisis y modelaje

de datos complejos, mapas interactivos

y la suma de gran variedad de datos con

información geoespacial 


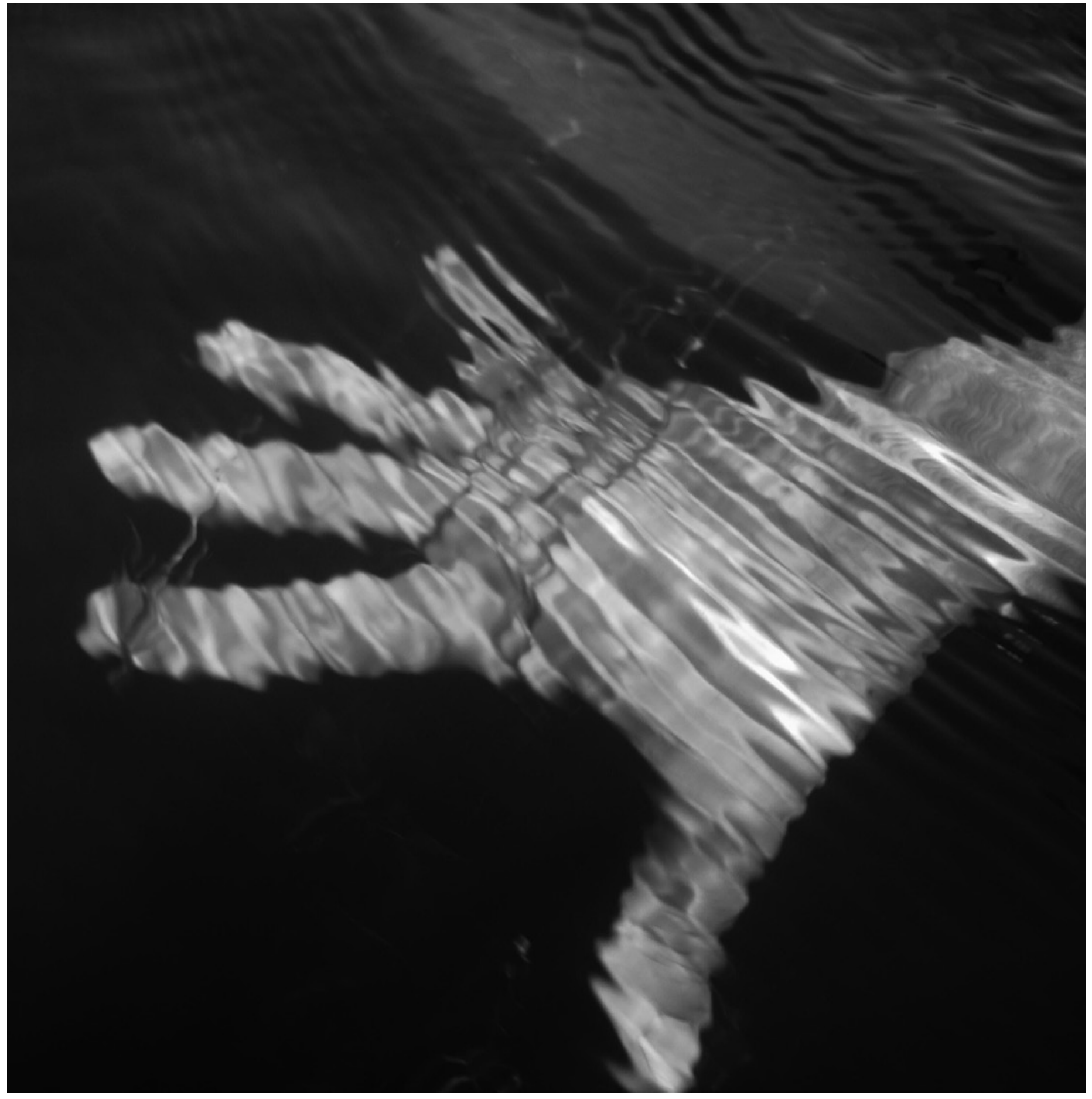

() Laura Malachesky 
Educación y accesibilidad. Transformaciones territoriales en pueblos sobre la base de las posibilidades de integración en la provincia de Chubut

El trabajo fue realizado con la finalidad de representar la relación que puede existir entre los distintos establecimientos educativos del departamento Tehuelches de la provincia del Chubut y la accesibilidad a los mismos. Para esto se tuvieron en cuenta las principales vías de comunicación, la calidad de los caminos y su situación respecto de las localidades de mayor tamaño demográfico. También se consideraron la conexión a Internet, telefonía celular y las opciones que estas herramientas suponen para las nuevas generaciones. El objetivo fue representar cómo las vías de comunicación pueden resultar un problema o una limitación ante las posibilidades de integración de los diferentes establecimientos educativos. La propuesta metodológica tomó como base un mapa político de la República Argentina dividido por jurisdicciones departamentales. La intención de representar el departamento Tehuelches en el contexto provincial tuvo la finalidad de mostrar cómo la red de caminos, en particular la Ruta Nacional $N^{\circ} 40$, integra las ciudades y pueblos. $Y$ algo más que resulta importante a considerar en cuanto a la conectividad de las diferentes localidades es la transitabilidad de los caminos en los meses de invierno ya que, por las condiciones meteorológicas y topográficas, la zona, durante este período de tiempo, cuenta con caminos poco transitables, sobre todo en ciertos sectores en los que los cerros no dejan que el hielo o la nieve, por encontrarse en umbrías, se descongele.

En síntesis, es posible identificar dos localidades dentro del departamento Tehuelches que por su ubicación son más dinámicas y cuentan con mejor calidad en la provisión de servicios, en particular de Internet y telefonía celular. Son las localidades de Gobernador Costa y José de San Martín. El aislamiento del resto de los pueblos y parajes (Imagen $\mathrm{N}^{\circ} 1$ ) no solo se observa en lo que respecta a las rutas y caminos sino también a las posibilidades de conexión a Internet. Desde ya que Internet y telefonía celular son herramientas fundamentales para integrar las diferentes localidades que permiten el crecimiento y desarrollo de los habitantes. El análisis de las variables de integración de los establecimientos educativos del departamento Tehuelches intentó exponer parte de las causas que explican el desarraigo y el envejecimiento de la población que cuenta con limitaciones en cuanto a las vías de comunicación. Este trabajo fue presentado por Ricardo Casares, quien además culminó sus estudios de grado de Licenciatura en Geografía con un trabajo sobre la accesibilidad a la educación en áreas de bajas densidades (Esc. № 97 Dr. Atilio Viglione, Esc. № 783 Río Pico).

Cambios territoriales en el área rururbana y rural de Trevelin El siguiente trabajo comparó imágenes satelitales combinadas y reproyectadas 2007 y 2011 en el sistema de coordenadas POSGAR
1994 faja 2, las que presentan combinación de banda RGB 542, con el objetivo de resaltar especialmente el área urbana de Trevelin. Esta combinación de bandas muestra las áreas urbanas (cemento) en tonos de magenta, las variaciones de vegetación en marrones, verdes y naranja; los cuerpos de agua en negro, y las nieves eternas en violeta. Se observaron modificaciones en varios cuerpos de agua, usos del suelo y estructura urbana. Metodológicamente, se utilizaron herramientas SIG integrando el modelo vectorial y modelo raster. El principal objetivo fue establecer los cambios territoriales en el área rururbana y rural de Trevelin a través de la comparación de imágenes combinadas y reproyectadas 2007 y 2011.

Las lagunas $\mathrm{N}^{\circ} 1$ y $\mathrm{N}^{\circ} 2$ son las más cercanas a la estructura urbana de Trevelin y se ubican en el área de inundación del río Percy. Por otra parte, se encuentran próximas al canal principal del consorcio de riego. El cuerpo de agua $\mathrm{N}^{\circ} 1$ es una laguna natural temporaria formada a partir de las precipitaciones. La laguna $N^{\circ} 2$ está ubicada al SO. Evidencia a través de su forma regular la mano del hombre. Se formó como consecuencia de la extracción de áridos para la construcción de la ruta de acceso a la Presa Futaleufú en los años 70, la que dejó cavas en las proximidades del pueblo. La laguna $\mathrm{N}^{\circ} 3$ está ubicada al este, próxima al río Corintos; es una laguna natural temporaria alimentada por arroyos y también por desbordes de este río. Este cuerpo de agua presentó una importante disminución en su área en la observación de las imágenes 2011. En este caso, en particular nos apoyamos en la herramienta deslizador del tiempo del Google Earth, la que nos permitió observar la temporalidad de la misma pero también confirmar la disminución de su superficie para el mismo mes en distintos años. Asimismo, pudimos observar la acción antrópica en su lecho. La laguna Brychan es una laguna natural alimentada subterránea y superficialmente, se ubica en la ladera del borde montañoso (453 m.s.n.m) a 4,5 km del casco urbano. Se inserta en un ambiente de cordillera con bosque nativo de ciprés, ñire y otras especies. Esta es una zona con características rural-urbanas, ya que se ven en el territorio producciones agrícolo-ganaderas intensivas y una creciente ocupación residencial (Imagen $\mathrm{N}^{\circ} 2$ ). Este estudio posibilitó realizar un análisis preliminar sobre el avance de la ciudad sobre áreas potencialmente productivas. Problemática presentada por César Barros Hurtado (Esc. № 705 y 740); Norma Noemí Gajardo (Esc. № 705), y María Rosa Schwarz (Esc. № 705 y 708), Trevelin y Esquel.

\section{Valoración del estado de conservación del Cordón Situación y cuerpos de agua aledaños entre los años 2007 y 2011}

El presente estudio comprende las lagunas Larga, Terraplén, Trafipan, el lago Krugger y parte de los lagos Futalaufquen y Amutui Quimei, en el sector oeste de la provincia de Chubut, en cercanías a las ciudades de Esquel y Trevelin. El cordón montañoso en cuestión se localiza al oeste de la Ruta Provincial № 71 (RP № 71), 
Imagen $\mathrm{N}^{\circ} 1$. Accesibilidad e integración educativa en el departamento Tehuelches, Chubut.

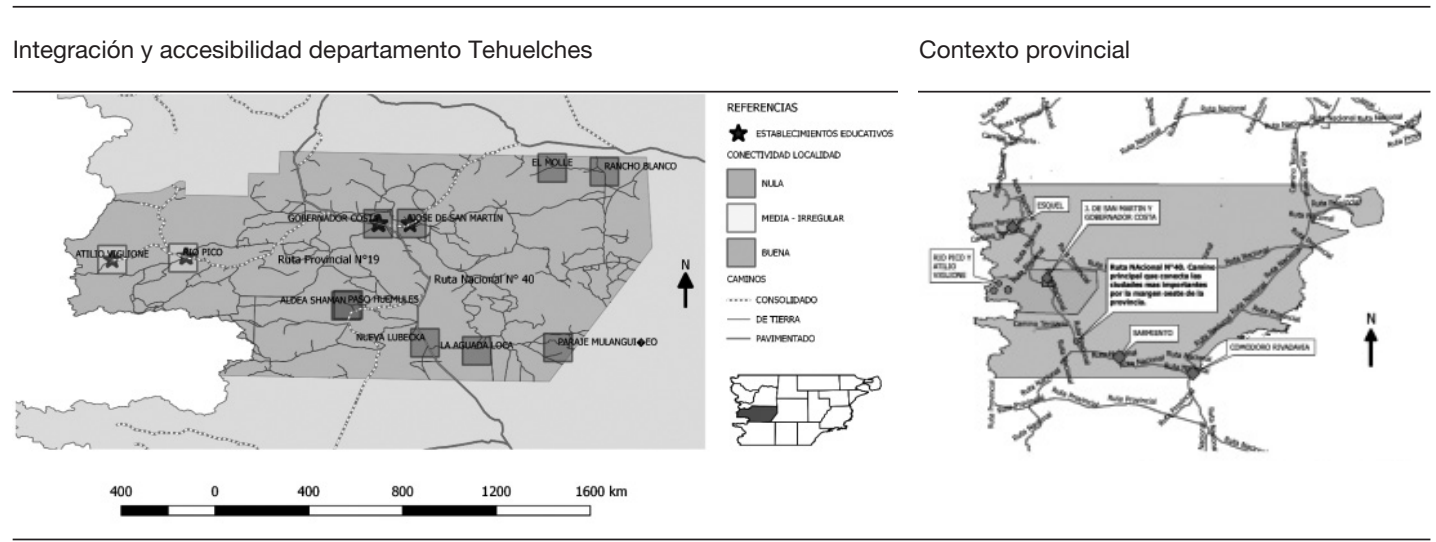

Fuente: elaboración propia. Datos del IGN.

\section{Imagen $\mathbf{N}^{\circ}$ 2. Cambios territoriales en Trevelin, Chubut.}

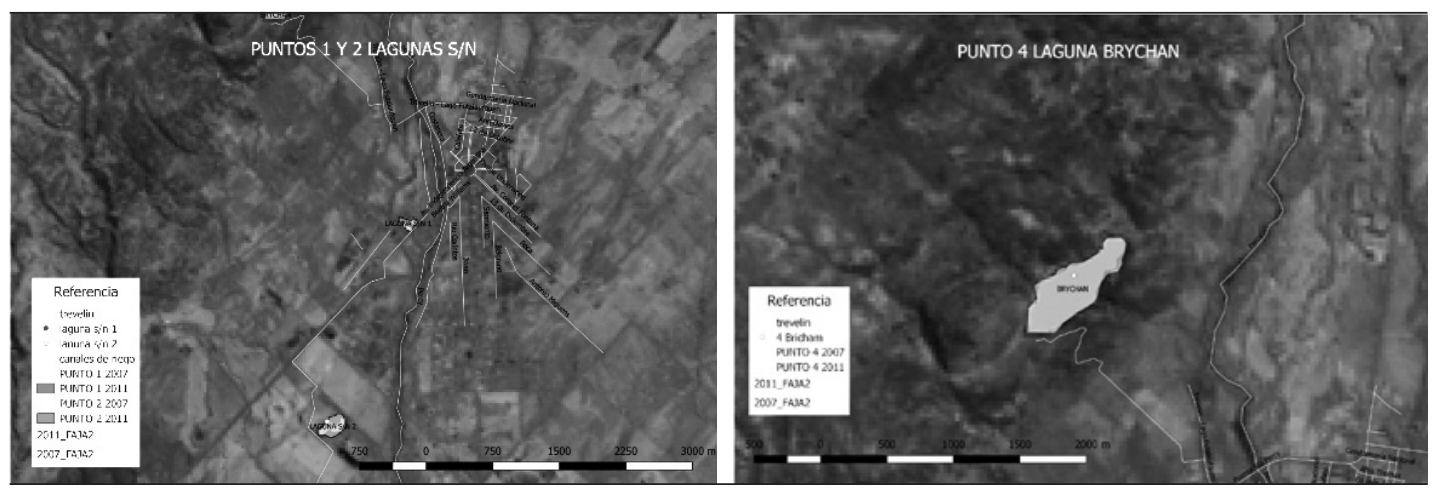

Fuente: elaboración propia. Datos del IGN. Imágenes Landsat TM 52007 y 2011.

presenta una orientación aproximadamente NNO-SSE, unos $26 \mathrm{~km}$ a lo largo del rumbo, y se encuentra ubicado dentro del Parque Nacional Los Alerces, al igual que los lagos; se destacan en él los cerros Dedal, Cocinero, Situación y La Monja, entre otros. Con respecto a las lagunas, las mismas se encuentran fuera del área del Parque Nacional y se trata de cuerpos menores, ubicados al este de la RP $\mathrm{N}^{\circ} 71$ (Imagen $\mathrm{N}^{\circ} 3$ ). El objetivo fue evaluar el estado de conservación del área de estudio y observar la existencia de variaciones en los cuerpos de agua, la presencia de nieve y la vegetación entre los años 2007 y 2011.

La propuesta metodológica para el caso de estudio fue el análisis multitemporal basado en el uso de imágenes de satélite del tipo Landsat 5 TM de los años 2007 y 2011, que permitieron observar los cambios en las variables de interés. En síntesis, en un período de cuatro años se observó: disminución de las superficies de las lagunas Terraplén y sin nombre y del lago Krugger. Aumento de la superficie de las lagunas Larga y Trafipan y de los lagos Amutui Quimei y Futalaufquen. Evidente disminución de las masas de nieve en las altas cumbres. Esta variable parece ser la más vulnerable a los cambios climáticos. Mejor conservación del bosque al oeste del cordón; dicho cordón actúa como barrera orográfica y las mayores precipitaciones descienden al oeste del mismo. Esto origina un bosque más denso y vigoroso en el sector oeste en comparación con el sector este. Temática presentada por Francis Gauman (UNLP, La Pampa), Stefania Ruiz (ISFD Nº 809 Esquel), y Pamela Trafipan (ISFD Nº 809 Esquel).

\section{Incendio "Las Horquetas": estimación de impacto}

Esta temática fue presentada por Lucía Molina, del Área de Protección Forestal del Centro de Investigación y Extensión Forestal Andino Patagónico (CIEFAP), y Pedro Agustín Noli, de la Facultad Ciencias Naturales de la Universidad Nacional de la Patagonia San Juan Bosco (UNPSJB), sede Esquel. Durante el verano de 20142015, se sucedieron en el oeste de la provincia del Chubut grandes incendios que se estima abarcaron una superficie mayor a 40.000 hectáreas (fuentes no oficiales) y afectaron áreas de jurisdicción 
Imagen $\mathbf{N}^{\circ} 3$.

Mapa cuerpos de agua alrededor del Cordón Situación

Fuente: elaboración propia. Datos del IGN. Imágenes satelitales TM 5 2007-2011.

tanto nacional (Parque Nacional Los Alerces, Parque Nacional Lago Puelo) como provincial (lago Cholila, río Turbio y Puerto Patriadas, Epuyén). Los incendios se han asociado a un año (2014) extraordinariamente seco con un valor de precipitaciones anuales tres veces menor al promedio desde mediados de siglo, combinado con una elevada carga de material combustible compuesto por la caña coligüe seca luego del evento de floración masiva ocurrido en 2013. El objetivo del trabajo fue estimar la superficie afectada por el incendio en el lago Cholila, del verano de 2015, denominado "Las Horquetas" y determinar las cuencas y las áreas protegidas afectadas por el incendio.

El total de área afectada por el incendio "Las Horquetas" no se ha conocido por fuentes oficiales y las estimaciones publicadas por las distintas fuentes mediáticas resultaron muy diversas y poco certeras. Debido a la elevada importancia del lago Cholila (tanto socioeconómica, por la población que alberga y las actividades económicas que sostiene, como de conservación, por ser cabecera de la cuenca Futaleufú, que incluye el área protegida Parque Nacional Los Alerces), el conocimiento de los impactos del siniestro resulta imperante para la evaluación de daños y la generación de políticas protectoras. El área afectada por el incendio "Las Horquetas" se estimó en 24.400 hectáreas. Se quemaron cuencas completas de numerosos arroyos y ríos de montaña, desde sus cabeceras en las cumbres hasta sus desembocaduras en el lago Cholila. El fuego no alcanzó áreas de jurisdicción de parques nacionales aunque afectó la cuenca hidrográfica del río Futaleufú, de vital importancia en la dinámica de los ecosistemas del Parque Nacional Los Alerces. Esto deberá ser atendido en el futuro, puesto que el lago Cholila constituye la cabecera de dicha cuenca, y el volumen de vegetación perdida por el siniestro podría afectar significativamente el flujo de sólidos y nutrientes aguas abajo.
Imagen $\mathbf{N}^{\circ}$ 4. Análisis temporal del incremento del suelo desnudo tras el incendio

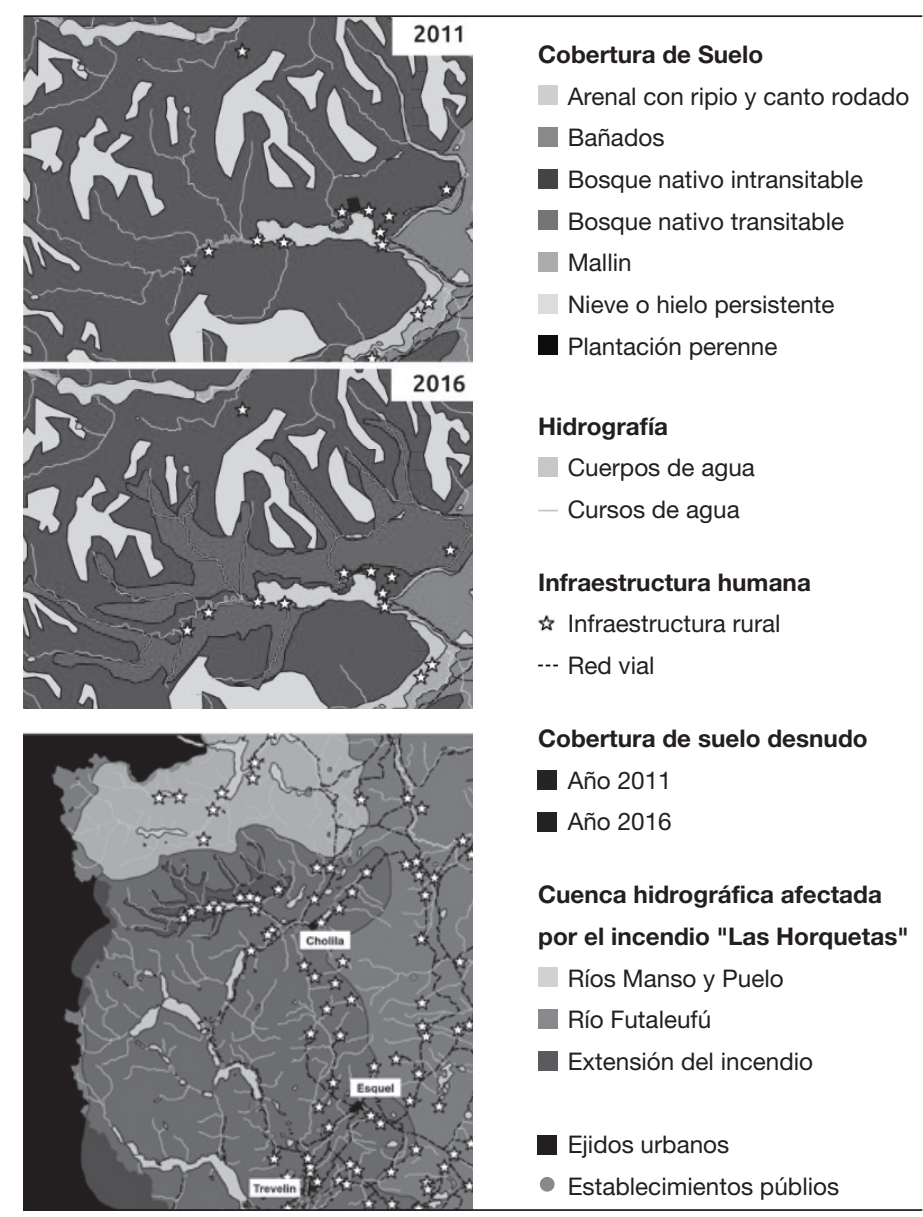

Fuente: elaboración propia. Datos del IGN. Imágenes Landsat TM 52007 y 2011. 


\section{Transitabilidad de los pasos fronterizos de Chubut}

Durante el período de invierno, en la provincia del Chubut se suspenden o modifican los estados de los pasos fronterizos. Por lo general se decide el corte total de algunas rutas de la zona como forma de prevenir accidentes por la acumulación de nieve, ráfagas de viento blanco y áreas anegadas. Los operativos de cierre de las rutas y los pasos fronterizos dependen del trabajo en conjunto de la Gendarmería Nacional, Vialidad Provincial y Nacional y la policía local. Es necesaria la elaboración de reportes y mapas de estado sobre la transitabilidad de los pasos y las rutas para mantener informada a la sociedad y explicar recaudos para transitar.

\section{Ordenamiento territorial para el análisis de la frontera urbana y los bosques nativos en Trevelin-Chubut}

La constante expansión producto del crecimiento urbano se viene realizando a expensas del bosque y la tala indiscriminada a la que está sometida la región sur de Argentina, que en muchos casos es irregular y produce el constante empobrecimiento de la flora y la fauna. Las causas que han provocado la pérdida del bosque nativo son: los incendios forestales, la tala para obtención de madera, el sobrepastoreo, las urbanizaciones no planificadas y la invasión de especies exóticas, entre otras. En el trabajo se resalta la problemática vinculada a la expansión urbana sobre el bosque nativo, que en muchos de los casos de incendios complejiza la situación para la extinción del fuego. Los servicios ambientales que brindan los bosques nativos pueden colapsar si continúa disminuyendo su superficie y continuidad. Es así que se plantea la necesidad de legislar normas que los protejan. Aquí se plantea la necesidad de la colaboración entre distintas dependencias del Municipio, como son la Dirección General de Bosques y la Dirección de Catastro, para realizar normativas que contemplen los riesgos de la urbanización al interior del bosque.

\section{Manejo de las canteras en áreas cercanas a la estructura urbana en la ciudad de Esquel}

El presente proyecto consiste en el análisis de las problemáticas vinculadas a las canteras próximas a las áreas de expansión urbana. Las canteras de la zona son de extracción de material mixto, arena y ripio, a cielo abierto. El desarrollo de las canteras implicó desmonte y acopio de la cobertura vegetal para retirar el material, extracción mediante una pala cargadora y posterior traslado del mismo en camiones hasta su destino final. En las áreas de expansión se pueden observar deslizamientos y el uso del espacio como basureros irregulares debido a la falta de mantenimiento de las empresas involucradas. En consecuencia, se convirtió en un espacio de peligrosidad para el asentamiento humano y con deterioro del paisaje por el tipo de actividad.

\section{Localización óptima en la planta de Residuos Sólidos Urbanos}

Uno de los problemas que sufre el medio ambiente es resultado directo de la propia evolución de la sociedad: la producción de los residuos. Las actividades humanas generan distintos tipos de residuos de diferente composición, estado o peligrosidad. Según sus características, se debe pensar el tratamiento, gestión y almacenamiento de los mismos, lo que da lugar a la creación de infraestructuras de gestión con el fin de evitar cualquier deterioro ambiental. En este caso, el trabajo se centró en la localización óptima en el territorio para determinar un conjunto de lugares candidatos que pudieran acoger este tipo de instalaciones. Lo presentó un estudiante de la Tecnicatura en Gestión Ambiental como proyecto de intervención profesional, teniendo en cuenta que esta instancia es la práctica para generar proyectos de intervención en instituciones en las que el estudiante ya se encuentra inserto.

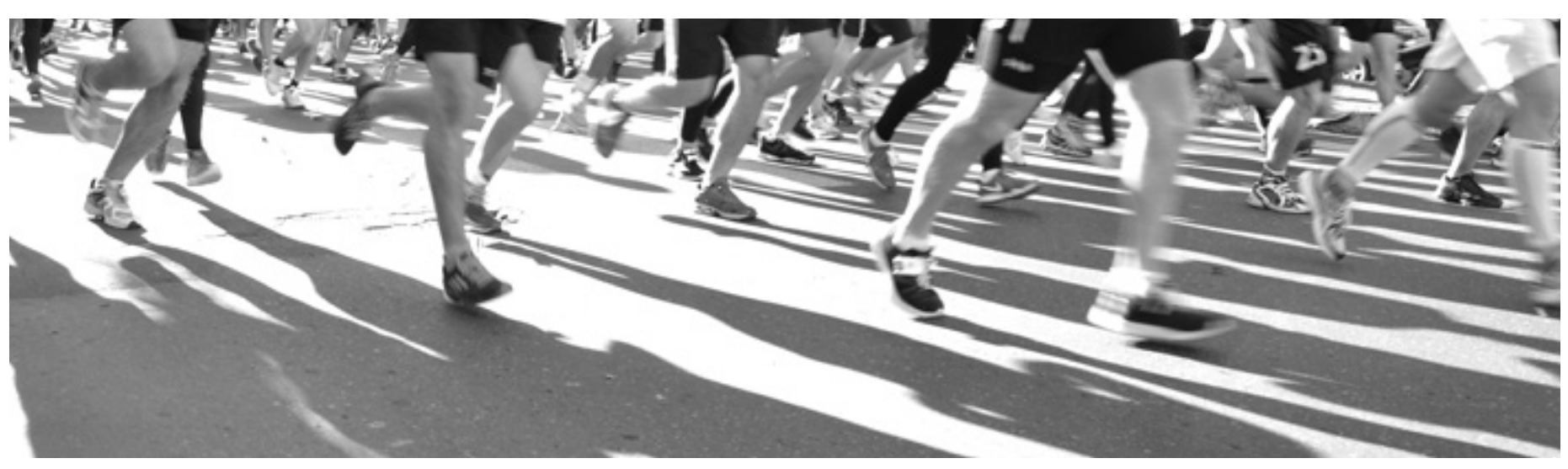




\section{Conclusiones}

La función social que asume la extensión universitaria es contribuir a la calidad de vida de la sociedad desde un diálogo interactivo y multidireccional sin jerarquización de los actores, donde se aporte a la transformación social. La unión entre la universidad y la sociedad contribuye a la producción de saberes científicos y culturales para la apropiación y resolución de problemáticas territoriales. La implantación de la extensión universitaria fuera del ámbito local admite introducir nuevos proyectos de docencia, y en este caso las Tecnologías de la Información Geográfica superan la enseñanza teórico-práctica con una metodología de aprendizaje grupal e interinstitucional. Este espacio generó no solo el conocimiento de la utilización de los SIG para resolver problemáticas socioambientales a partir del análisis espacial, sino también el tejido de relaciones para comprender y analizar los fenómenos territoriales desde diversas perspectivas, superando de manera grupal las limitaciones de los SIG.

Por otro lado, la experiencia permitió acceder a relaciones directas entre los actores involucrados en distintas áreas de gestión municipal para la intervención de los proyectos de los estudiantes en el área específica que correspondiera, y de esta manera se crearon los espacios de práctica profesional.

La experiencia llevada a cabo muestra la importancia de la generación de equipos de trabajo con problemáticas asociadas y de respetar estándares para la integración de la información geoespacial creada por distintas instituciones. Este planteamiento encuentra sus fundamentos en los cambios científicos y tecnológicos que se han producido en los últimos años y que han transformado los espacios de la actividad humana, lo que algunos autores denominan la "revolución científico-tecnológica". En este contexto es imprescindible incorporar, en todos los ámbitos, estrategias y recursos que garanticen el acceso al uso y al manejo de las nuevas tecnologías. En este caso, el análisis espacial de las problemáticas ambientales a través de un software de código abierto posibilita la utilización e implementación de información geoespacial para las instituciones que gestionan decisiones territoriales como también para fines didácticos en la educación media y superior.

La sociedad actual demanda aprender y manejar información geográfica cada vez más compleja. Es indispensable saber leer, interpretar y construir mapas dinámicos que hagan factible conocer diferentes territorios. Es un gran desafío exponer los productos en diversos eventos organizando espacios creativos de interacción y análisis de problemáticas regionales, haciendo énfasis en el estudio integral de los fenómenos territoriales. En síntesis, el curso proporcionó la posibilidad de participar en eventos académicos y dentro del ámbito laboral para establecer espacios de debate sobre la información geoespacial, las aplicaciones y la integración cartográfica.

\section{Referencias bibliográficas}

Bejarano, C. (2011). Los actores de la Extensión Universitaria. Un Saber Hacer para la construcción de un enfoque CTS. XI Congreso Iberoamericano de extensión universitaria. Santa Fe, Argentina

Buzai, G. D. (2010). Geografía y Sistemas de Información Geográfica: Aspectos conceptuales y aplicaciones. Buenos Aires: GESIG.

(2016). Sistemas de Información Geográfica. Cartografía temática y análisis espacial. Buenos Aires: Lugar.

Chuvieco, E. (2008). Teledetección Ambiental. La observación de la Tierra desde el Espacio. $3^{a}$ ed. actualizada. Madrid: Ariel Ciencia.

Llanes Guerra J. (2010). Cuba: Los centros de gestión para la reducción de riesgo. Disponible en: www.undp.org.cu/crmi

Masot, A. (2010). El uso didáctico de los sistemas de información geográfica en el Espacio Europeo de Educación Superior. Tejuelo, (9), 136-161.

Quiroz Ortuño, Y. (2010). Los SIG como herramienta para la toma de decisiones en la solución de problemas ambientales y dentro de la formación profesional en ciencias ambientales. Temas de Ciencia y Tecnología, 14(41). 33-40. Universidad de la Sierra Juárez.

Zappettini, M. (2007). Enseñanza de la geografía e Informática: El uso del SIG en una experiencia pedagógica innovadora. Geograficando, 3(3). Disponible en: http://www. fuentesmemoria.fahce.unlp.edu.ar/art_revistas/pr.3674/pr.3674.pdf 